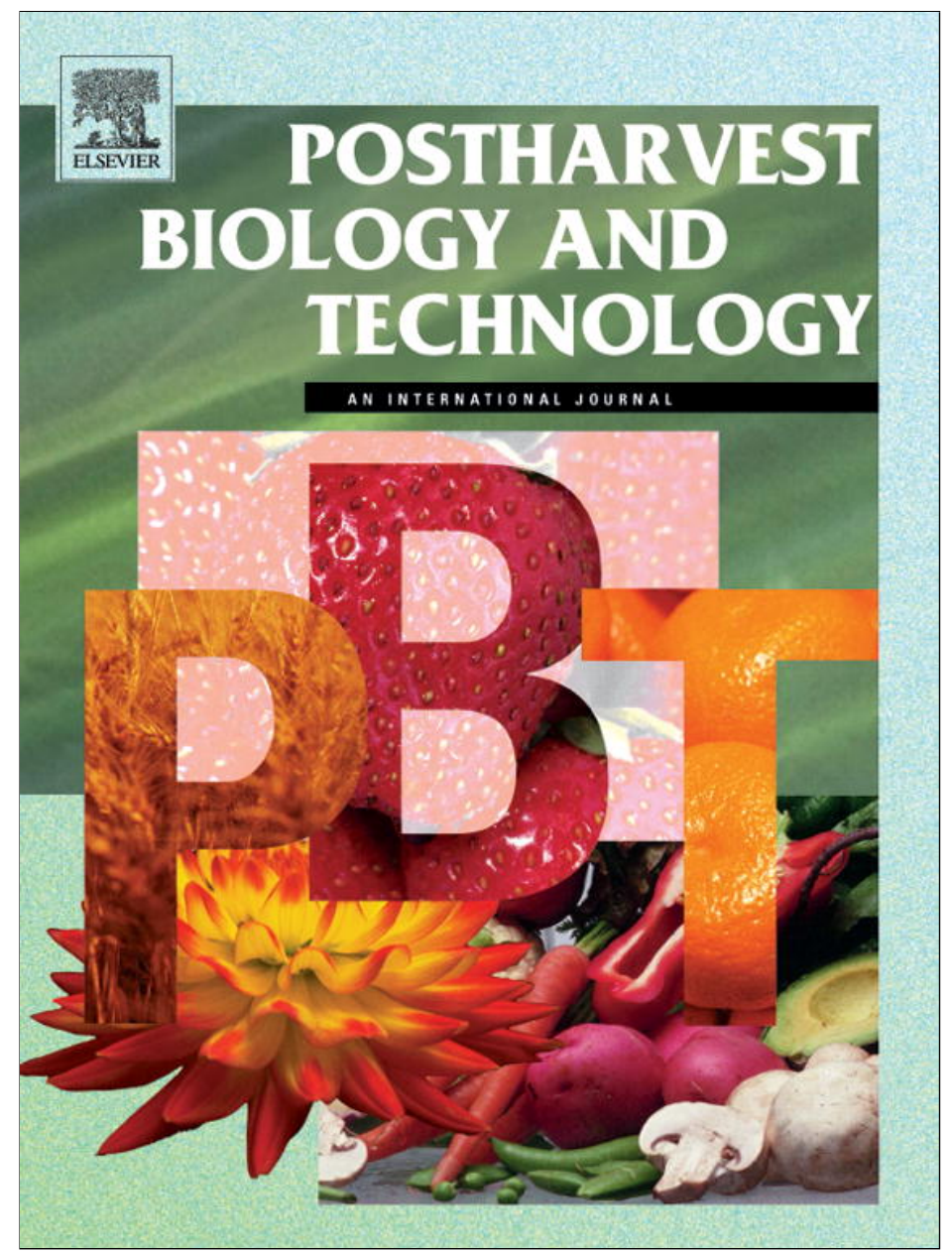

(This is a sample cover image for this issue. The actual cover is not yet available at this time.)

This article appeared in a journal published by Elsevier. The attached copy is furnished to the author for internal non-commercial research and education use, including for instruction at the authors institution and sharing with colleagues.

Other uses, including reproduction and distribution, or selling or licensing copies, or posting to personal, institutional or third party websites are prohibited.

In most cases authors are permitted to post their version of the article (e.g. in Word or Tex form) to their personal website or institutional repository. Authors requiring further information regarding Elsevier's archiving and manuscript policies are encouraged to visit: 


\title{
The control of postharvest blue and green molds of citrus in relation with essential oil-wax formulations, adherence and viscosity
}

\author{
Kouadio Hugues Sosthène Kouassi ${ }^{\text {a,b,*,1 }}$, Mohammed Bajji ${ }^{a, 1,2}$, Haïssam Jijakli ${ }^{\text {a }}$ \\ a Phytopathology Unit, Gembloux Agro-Bio Tech, Liege University, Passage des Déportés, 2, B-5030 Gembloux, Belgium \\ ${ }^{\mathrm{b}}$ Laboratory of Chemistry and Biochemistry of Natural Products, Faculty of Science and Technology, Cheikh Anta Diop University, BP 5005 Dakar-Fann, Senegal
}

\section{A R T I C L E I N F O}

\section{Article history:}

Received 27 March 2012

Accepted 20 June 2012

\section{Keywords:}

Essential oil

Citrus fruit

Biological activity

Penicillium italicum

P. digitatum

Wax

\section{Introduction}

The antifungal properties of essential oils (EOs) have been known for a long time, and studies on their effects on several postharvest phytopathogens have been reported (Bakkali et al., 2008; Sanchez-Gonzalez et al., 2011; Marei et al., 2012). Antifungal tests in in vitro conditions of several EOs and their compounds (Daferera et al., 2003; Linde et al., 2010; Soylu et al., 2010; Marei et al., 2012; Kouassi et al., in press) showed that they can (i) be active against some types of phytopathogenic fungi and not active against others, (ii) be active against the same pathogen, but not at the same concentration, and (iii) exhibit antifungal activity against a certain pathogen in one fruit type, but not against the same pathogen in another fruit type, or at least not at the same concentration. Furthermore, complexity of EOs and their compounds make the study of their mechanisms of action difficult. Nevertheless, the potential use of EOs to control postharvest diseases requires

\footnotetext{
* Corresponding author at: Phytopathology Unit, Gembloux Agro-Bio Tech, Liege University, Passage des Déportés, 2, B-5030 Gembloux, Belgium. Tel.: +32 0477063353; fax: +32081610126.

E-mail address: sosthenehugues@yahoo.fr (K.H.S. Kouassi).

1 These authors have equally contributed to this work.

2 Present address: Bioengineering Unit, Life Sciences Department, Walloon Agricultural Research Centre (CRA-W), Chaussée de Charleroi 234, B-5030 Gembloux, Belgium.
}

a detailed examination of their biological activity and the development of formulations which inhibit the growth of pathogens at non-phytotoxic concentrations. In order to develop EO-based fungicide formulations as postharvest treatments, a study was conducted on the antifungal activity in in vitro conditions of thirty EOs against Penicillium italicum Wehmer, Penicillium digitatum Sacc and Colletotrichum musea (Berk. \& M.A. Curtis) Arx, three postharvest fungal pathogens of fruit (Kouassi et al., in press). It showed that Cinnamomum zeylanicum, Cinnamomum verum and Eugenia caryophyllata EOs were still effective at $100 \mathrm{ppm}$ against the three tested pathogens. In another study (Kouassi et al., 2010), the in vivo activity of these three EOs against $P$. digitatum and $P$. italicum on orange fruit (preventive treatment) showed that C. zeylanicum, C. verum and E. caryophyllata EOs diluted in ethanol were able to either partially (at a concentration $<5 \%$ ) or totally (at a concentration $\geq 5 \%$ ) protect fruit from infections of both pathogens. Furthermore, no visible damage was observed on the orange cuticle or skin up to $5 \%$ of each EO. Among the three EOs, C. zeylanicum was the most effective. These results are interesting from a scientific point of view. However, the practical application of these EOs as an alternative to chemical fungicides is not yet feasible because to be effective, excessive concentrations are still needed. In addition, the method used for fruit treatment (local treatment of wound sites) is not applicable under conditions of fruit export and marketing. Therefore, for EO-based fungicides to become realistic alternatives to chemical fungicides in citrus postharvest management, it is 
necessary to find appropriate methods of EO application for protection of citrus fruit under commercial conditions.

Chemical treatments are traditionally considered to be the cheapest and the most effective methods for postharvest disease control. The fruit industry (CERAFRUIT S.L., TECNIDEX S.A., and FECOPA SARL) uses chemical fungicides at effective concentrations of less than $1 \%$ for the protection of citrus fruit. To develop a competitive alternative, it is also necessary that such methods of application allow a reduction in effective concentration of EOs. One disadvantage of EOs is their volatility. They volatilize and degrade quickly even at room temperature. Several studies have shown that in in vitro conditions, EOs are excellent biofungicides against plant pathogens and some are even better than chemical fungicides (Ranasinghe et al., 2002; De Sousa et al., 2011; Şerban et al., 2011). Under in vitro conditions, EOs are generally effective from $0.01 \%$ or less (Bakkali et al., 2008; Combrinck et al., 2011). According to other studies (Plotto et al., 2003; Kouassi et al., 2010, in press), however, results obtained in in vivo conditions showed a significant decrease in EO efficiency compared to in vitro conditions. This decrease in efficiency is due to greater volatility of EOs in in vivo than in in vitro conditions. Moreover, in vitro conditions provide a greater contact area between EOs and pathogens and thus allow for better effectiveness. Therefore, a product (i) allowing a closer contact between EOs and fruit surface and (ii) preventing them from volatilizing, will provide better protection of fruit by EOs at low concentrations.

Natural or synthetic food grade waxes are used for coating in the food industry. They have visual characteristics and gas permeabilities which are particularly advantageous, especially for control of weight loss, maturation and quality of coated fruit and vegetables (Sanchez-Gonzalez et al., 2011). The incorporation of EOs in waxes for the coating of postharvest citrus fruit can be a solution. Du Plooy et al. (2009) showed that Lippia scaberrima EO (at 0.25\%) in combination with carnauba tropical wax has provided either $100 \%$ (preventive treatment) or 95\% (curative treatment) disease control against $P$. digitatum infection of citrus fruit. These results were encouraging and strengthened our objective to study the antifungal (preventive and curative) effects of $C$. zeylanicum in combination with different types of commercial wax. Antifungal effects of a mixture of $C$. zeylanicum and alcohol or Simulgel were also evaluated against $P$. digitatum and $P$. italicum infections. Simulgel is a thickening and emulsifying polymer which is often used in cosmetics to solubilize EOs into water-based products. In addition, viscosity and the volume of EO formulations that adhere to the fruit surface were assessed.

\section{Materials and methods}

\subsection{C. zeylanicum EO-based formulations}

C. zeylanicum EO-ethanol formulation: C. zeylanicum was produced by Pranarôm international SA (Ghislenghien, Belgium). Final EO-ethanol formulations contained $0.1-0.5 \%$ C. zeylanicum $\mathrm{EO}$ and $1.5 \%$ ethanol in distilled water.

C. zeylanicum EO-Simulgel formulation: Simulgel is easy to use in a liquid form. Final concentrations contained $0.1 \%$ or $0.5 \%$ C. zeylanicum $\mathrm{EO}$ and $1.5 \%$ Simulgel in water.

C. zeylanicum EO-wax formulations: Seven commercial waxes were used, including XEDASOL M7 (Xeda International S.A., Andiol, France) made of shellac, carnauba wax, and fatty acids (shellac-carnauba-fatty acids); XEDASOL M15 (Xeda International S.A., Andiol, France) made of shellac and carnauba wax (shellac-carnauba); XEDAFOS L (Xeda International S.A., Andiol, France) made of shellac (shellac); XEDASOL EC2 (Xeda International S.A., Andiol, France) made of carnauba wax (carnauba); 95369-1L
(Sigma-Aldrich NV/SA, Belgium) made of paraffin wax (paraffin) and Michem ${ }^{\circledR}$ emulsion 18325 (Michelman, Aubange, Belgium) made of polyethylene wax (polyethylene). EO-wax formulations were composed of wax solution supplemented with $C$. zeylanicum at $0.1 \%$ or $0.5 \%(\mathrm{v} / \mathrm{v})$.

\subsection{Pathogens}

P. italicum (strain PIRBM1) and P. digitatum (strain PDRBM1) were obtained from the Plant Pathology Unit collection (Gembloux Agro-Bio Tech, Belgium). Penicillium strains were isolated from citrus in Morocco (ENA, Meknes). A 14-d-old culture of these strains at $25^{\circ} \mathrm{C}$ grown on potato dextrose agar (PDA) was used as conidia source. Conidia were scrapped from the agar and suspended in distilled water with $0.05 \%$ Tween $20(\mathrm{v} / \mathrm{v})$, then the suspension concentration (inoculum) was adjusted to $10^{4}$ conidia/mL using a haemocytometer (Bürker cell).

\subsection{Citrus fruit treatment and artificial infections}

Mature healthy untreated organic orange fruit were used in the present work. Fruit were surface disinfected by dipping for $2 \mathrm{~min}$ in a $10 \%$ sodium hypochlorite solution and were rinsed twice with distilled water before being dried overnight at ambient temperature. Each fruit was wounded on the outer surface on three locations at the same side to a depth of $3 \mathrm{~mm}$ and a diameter of $5 \mathrm{~mm}$ using a cork borer. Ten oranges per treatment were used.

Preventive treatments were carried out by dipping wounded fruit for 2 min into the specific formulations previously described (C. zeylanicum EO-ethanol, C. zeylanicum EO-Simulgel or C. zeylanicum EO-wax) and allowed to air dry for 4 or $24 \mathrm{~h}$. Thereafter, each wound site was infected by inoculating $25 \mu \mathrm{L}$ of the inoculum of $P$. digitatum or P. italicum. Finally, each fruit was placed in a plastic tray containing a filter paper and $3 \mathrm{~mL}$ of sterile water to ensure high relative humidity, and then stored at $23^{\circ} \mathrm{C}$. Controls consisted of fruit treated with distilled water, ethanol, Simulgel or wax at the same concentrations as the ones used in formulations. A treatment with a chemical fungicide thiabendazole (TBZ) usually used by FECOPA SARL (Casablanca, Morocco) at $0.4 \%$ in wax (citrashine) for citrus postharvest treatment was also included.

For curative treatments, fruit were wounded as above, then inoculated with P. italicum ( $25 \mu \mathrm{L}$ of inoculum per wound site) and incubated for $24 \mathrm{~h}$ at $23^{\circ} \mathrm{C}$. Fruit were after that treated as previously described and again incubated in the same conditions as for preventive treatments. Two independent experiments were performed for both preventive and curative treatments.

The effect of treatments (preventive and curative) was evaluated after $7 \mathrm{~d}$ of fruit incubation, and data were recorded as the percentage of disease control according to the formula $\left(\mathrm{WI}_{c}-\mathrm{WI}_{t}\right) / \mathrm{WI}_{c} \times 100$, where $\mathrm{WI}_{c}$ and $\mathrm{WI}_{t}$ represent wound incidence for the control (distilled water) and for the treatment, respectively. Wound incidence was determined as the number of rotten wounds for a studied treatment per total number of wounds for the same treatment.

\subsection{Volume of treatment per orange}

The volume of treatment used per orange, which represent the volume of treatment that remains on the fruit skin, was determined by an empirical method according to the formula $\left(V_{i}-V_{f}\right) / N_{t}$, where $V_{i}$ is the initial volume before soaking fruit $(500 \mathrm{~mL} /$ treatment $), V_{f}$ is the final volume after soaking and $N_{t}$ is the number of fruit soaked (20/treatment). Three independent experiments were performed. 
Table 1

Incidence of blue and green molds of citrus on oranges by C. zeylanicum essential oil (EO) amended with ethanol applied $4 \mathrm{~h}$ before inoculation with $P$. italicum or $P$. digitatum.

\begin{tabular}{|c|c|c|c|c|}
\hline \multirow[t]{2}{*}{ Treatment ( $4 \mathrm{~h}$ before inoculation) } & \multicolumn{2}{|c|}{ Blue mold (P. italicum) } & \multicolumn{2}{|c|}{ Green mold ( $P$. digitatum) } \\
\hline & Wound incidence $^{\mathrm{a}}$ & Disease control (\%) & Wound incidence $^{\mathrm{a}}$ & Disease control (\%) \\
\hline Distilled water (control) & $1.00 \mathrm{a}$ & 0 & $1.00 \mathrm{a}$ & 0 \\
\hline Ethanol & $1.00 \mathrm{a}$ & 0 & $1.00 \mathrm{a}$ & 0 \\
\hline C. zeylanicum EO-ethanol (0.1\%) & $0.80 \mathrm{~b}$ & 20 & $1.00 \mathrm{a}$ & 0 \\
\hline C. zeylanicum EO-ethanol (0.2\%) & $0.80 \mathrm{~b}$ & 20 & $1.00 \mathrm{a}$ & 0 \\
\hline C. zeylanicum EO-ethanol (0.3\%) & $0.80 \mathrm{~b}$ & 20 & $1.00 \mathrm{a}$ & 0 \\
\hline C. zeylanicum EO-ethanol (0.4\%) & $0.80 \mathrm{~b}$ & 20 & $0.90 \mathrm{~b}$ & 10 \\
\hline C. zeylanicum EO-ethanol (0.5\%) & $0.43 c$ & 57 & $0.60 \mathrm{c}$ & 40 \\
\hline Thiabendazole (0.4\%)-water & $0.00 \mathrm{~d}$ & 100 & $0.00 \mathrm{~d}$ & 100 \\
\hline
\end{tabular}

a Wound incidence was determined from two independent experiments.

Values in the same column marked with different letters are significantly different at $P \leq 0.05$.

\subsection{Rotational rheological analysis}

Rheological measurements of C. zeylanicum EO formulations (EO-ethanol, EO-Simulgel, and EO-wax) were performed in duplicate by a rotational viscometer (Bohlin Instruments CVO50 Rheometer) fitted with a thermostatic bath for temperature control. An integrated computer controller was used to program the tests and the sensor System CVO utilizing a cone/cylinder configuration was used for measurement. Each formulation sample $(3 \mathrm{~mL})$ was placed in the sensor system for measurement at $25^{\circ} \mathrm{C}$. Curves of instantaneous viscosity ( $\mathrm{mPa}$ ) as a function of the shear rate $(D)$ were obtained with the following program: $5 \mathrm{~min}$ from 0 to $300 \mathrm{~s}^{-1}$ (the maximum shear rate). Viscosity of each formulation at $10 \mathrm{~s}^{-1}$ and $300 \mathrm{~s}^{-1}$ was determined from the curve.

\subsection{Statistical analysis}

Statistical analysis of variance (ANOVA) was performed using the SAS software and means were separated using the Least Significant Difference (LSD) test at $P \leq 0.05$.

\section{Results and discussion}

\subsection{Citrus fruit treatment and artificial infection}

We first studied the preventive action of ethanol-C. zeylanicum EO (0.1-0.5\%) treatments against $P$. italicum and $P$. digitatum infections (Table 1). Distilled water and TBZ $(0.4 \%)$ treatments were also considered. TBZ was diluted in distilled water before being used. Pathogen inoculations were done $4 \mathrm{~h}$ after fruit treatment. The pathogenicity of $P$. italicum and $P$. digitatum was confirmed by the presence (all wounds were rotten) respectively of blue and green molds on orange fruit treated with distilled water (control). Like distilled water, ethanol treatment at $1.5 \%$ has no effect against the two fungi ( $0 \%$ disease control). Preventive dip treatment with $C$. zeylanicum EO-ethanol formulations significantly reduced wound incidence against both pathogens compared to the control, except in the case of $P$. digitatum where wound incidence by $C$. zeylanicum $\mathrm{EO}$ at $0.1-0.3 \%$ was as for the control. C. zeylanicum EO at $0.5 \%$ in ethanol was the most effective with a disease control of $57 \%$ (blue mold) and $40.0 \%$ (green mold). This result showed that in in vivo conditions, C. zeylanicum $\mathrm{EO}$ at $0.5 \%$ mixed with ethanol was partially effective, while in in vitro conditions, this EO even at $0.01 \%$ offered total pathogen inhibition (Kouassi et al., in press). The fact that, for high-volume formulation, a homogenous aqueous dispersion was difficult to obtain by mixing $1.5 \%$ ethanol with EO could have affected the effectiveness of $\mathrm{EO}$ in in vivo conditions. For the other concentrations $(0.1-0.4 \%)$ of $C$. zeylanicum EO, disease control was equal or lower than $20 \%$ for both diseases.

According to the literature (Teuscher et al., 2005), the main compounds of this EO are: cinnamaldehyde (42-82\%), eugenol (1-11\%), cinnamic alcohol (8\%), cinnamic acid (10\%), cinnamyl acetate, omethoxycinnamaldehyde, benzyl benzoate, linalool and safrole (up to $2 \%$ ). Cinnamaldehyde and eugenol are known to have strong antifungal activity (Sheng-Yang et al., 2005; Amiri et al., 2008; Sen-Sung et al., 2008; Campaniello et al., 2010; Matan et al., 2011; Moon et al., 2011). The biological activity of $C$. zeylanicum EO may be due to the synergistic action of these two compounds (Tsair-Bor and ShangTzen, 2008). However, it was reported that EO activity was mainly due to a synergistic or to antagonistic effects of its different compounds (Hummelbrunner and Isman, 2001; Bakkali et al., 2008; Sanchez-Gonzalez et al., 2011). It is thus possible that the activity of the main components is modulated by other minor molecules. Control of both diseases was much more enhanced by C. zeylanicum $\mathrm{EO}(0.5 \%)$-ethanol in the present work in which wounded fruit were treated by dipping whole fruit (40\% and $56.7 \%$, Table 1 ) compared to our previous work (Kouassi et al., 2010) in which treatment was applied at the wound site only (only $10 \%$ disease control). C. zeylanicum EO-ethanol formulation remains however still less efficient than the chemical fungicide treatment (100\% disease control) (Table 1). Moreover, ethanol itself is volatile and, therefore, would not allow maintaining the EO long enough on the skin of the orange to better protect it.

A second experiment was undertaken to evaluate preventive and curative treatments of Simulgel and the commercial waxes (shellac, carnauba, shellac-carnauba, shellac-carnauba-fatty acids, paraffin and polyethylene) supplemented with C. zeylanicum EO $(0.1 \%$ or $0.5 \%)$ against both pathogen infections. TBZ (0.4\%) supplemented with shellac was included as a standard fungicide treatment.

For the preventive effect, fruit treatment was carried out $4 \mathrm{~h}$ and $24 \mathrm{~h}$ before pathogen inoculation and the results are presented in Table 2. Whatever the time of inoculation, pathogenicity of $P$. italicum and $P$. digitatum was confirmed by the development respectively of blue and green molds on all infected wounds for distilled water, ethanol (1.5\%), Simulgel (1.5\%) and the commercial waxes (100\% incidence). In contrast, treatment with TBZ-shellac induced the highest disease control irrespective of the pathogen type and the inoculation time.

For formulations based on ethanol, Simulgel, paraffin or polyethylene supplemented with $C$. zeylanicum $\mathrm{EO}$ at $0.1 \%$, wound incidence was total (all wounds were rotten) except in the case of inoculation by P. italicum $4 \mathrm{~h}$ after treatment. In this case, wound incidence was not statistically different for all C. zeylanicum EO formulations at $0.1 \%$ presenting a disease control less than $27 \%$. For formulations based on wax (shellac, carnauba, shellac-carnauba or shellac-carnauba-fatty acids) supplemented with C. zeylanicum at $0.1 \%$, disease control was not better (equal or less than $10 \%$ ) in the case of inoculation by both pathogens $24 \mathrm{~h}$ after treatment and by P. digitatum $4 \mathrm{~h}$ after treatment.

With regard to treatment with C. zeylanicum EO at $0.5 \%$, wound incidence was greatly reduced in comparison with that of 
Table 2

Incidence of blue and green molds of citrus on oranges by C. zeylanicum essential oil (EO) formulations applied $4 \mathrm{~h}$ or $24 \mathrm{~h}$ before inoculation with P. italicum or P. digitatum (preventive treatment).

\begin{tabular}{|c|c|c|c|c|c|c|c|c|}
\hline \multirow[t]{3}{*}{ Treatment } & \multicolumn{4}{|c|}{ Blue mold (P. italicum) } & \multicolumn{4}{|c|}{ Green mold (P. digitatum) } \\
\hline & \multicolumn{2}{|c|}{$4 \mathrm{~h}$ before inoculation } & \multicolumn{2}{|c|}{$24 \mathrm{~h}$ before inoculation } & \multicolumn{2}{|c|}{$4 \mathrm{~h}$ before inoculation } & \multicolumn{2}{|c|}{$24 \mathrm{~h}$ before inoculation } \\
\hline & $\begin{array}{l}\text { Wound } \\
\text { incidence }^{\mathrm{a}}\end{array}$ & $\begin{array}{l}\text { Disease } \\
\text { control (\%) }\end{array}$ & $\begin{array}{l}\text { Wound } \\
\text { incidence }^{\mathrm{a}}\end{array}$ & $\begin{array}{l}\text { Disease } \\
\text { control (\%) }\end{array}$ & $\begin{array}{l}\text { Wound } \\
\text { incidence }^{\text {a }}\end{array}$ & $\begin{array}{l}\text { Disease } \\
\text { control (\%) }\end{array}$ & $\begin{array}{l}\text { Wound } \\
\text { incidence }^{\text {a }}\end{array}$ & $\begin{array}{l}\text { Disease } \\
\text { control (\%) }\end{array}$ \\
\hline Distilled water (control) & $1.00 \mathrm{a}$ & 0 & $1.00 \mathrm{a}$ & 0 & $1.00 \mathrm{a}$ & 0 & $1.00 \mathrm{a}$ & 0 \\
\hline Ethanol & $1.00 \mathrm{a}$ & 0 & $1.00 \mathrm{a}$ & 0 & $1.00 \mathrm{a}$ & 0 & $1.00 \mathrm{a}$ & 0 \\
\hline C. zeylanicum EO (0.1\%)-ethanol & $0.87 \mathrm{~b}$ & 13 & $1.00 \mathrm{a}$ & 0 & $1.00 \mathrm{a}$ & 0 & $1.00 \mathrm{a}$ & 0 \\
\hline C. zeylanicum EO (0.5\%)-ethanol & $0.53 c$ & 47 & $0.87 \mathrm{~b}$ & 13 & $0.6 c$ & 40 & $0.87 \mathrm{~b}$ & 13 \\
\hline Simulgel & $1.00 \mathrm{a}$ & 0 & $1.00 \mathrm{a}$ & 0 & $1.00 \mathrm{a}$ & 0 & $1.00 \mathrm{a}$ & 0 \\
\hline C. zeylanicum EO (0.1\%)-Simulgel & $0.80 \mathrm{~b}$ & 20 & $1.00 \mathrm{a}$ & 0 & $1.00 \mathrm{a}$ & 0 & $1.00 \mathrm{a}$ & 0 \\
\hline C. zeylanicum EO (0.5\%)-Simulgel & $0.33 d$ & 67 & $0.63 c$ & 37 & $0.43 d$ & 57 & $0.77 \mathrm{~b}$ & 23 \\
\hline Shellac-carnauba-fatty acids & $1.00 \mathrm{a}$ & 0 & $1.00 \mathrm{a}$ & 0 & $1.00 \mathrm{a}$ & 0 & $1.00 \mathrm{a}$ & 0 \\
\hline C. zeylanicum EO (0.1\%)-shellac-carnauba-fatty acids & $0.77 b$ & 23 & $0.90 \mathrm{~b}$ & 10 & $0.90 \mathrm{~b}$ & 10 & $1.00 \mathrm{a}$ & 0 \\
\hline C. zeylanicum EO (0.5\%)-shellac-carnauba-fatty acids & $0.10 \mathrm{e}$ & 90 & $0.37 d$ & 63 & 0.17 ef & 83 & $0.40 \mathrm{c}$ & 60 \\
\hline Shellac-carnauba & $1.00 \mathrm{a}$ & 0 & $1.00 \mathrm{a}$ & 0 & $1.00 \mathrm{a}$ & 0 & $1.00 \mathrm{a}$ & 0 \\
\hline C. zeylanicum EO (0.1\%)-shellac-carnauba & $0.77 \mathrm{~b}$ & 23 & $0.97 b$ & 3 & $0.93 b$ & 7 & $1.00 \mathrm{a}$ & 0 \\
\hline C. zeylanicum EO (0.5\%)-shellac-carnauba & $0.17 \mathrm{e}$ & 83 & $0.37 d$ & 63 & $0.25 \mathrm{e}$ & 75 & $0.40 \mathrm{c}$ & 60 \\
\hline Shellac & $1.00 \mathrm{a}$ & 0 & $1.00 \mathrm{a}$ & 0 & $1.00 \mathrm{a}$ & 0 & $1.00 \mathrm{a}$ & 0 \\
\hline C. zeylanicum EO (0.1\%)-shellac & $0.73 b$ & 27 & $0.90 \mathrm{~b}$ & 10 & $0.90 \mathrm{~b}$ & 10 & $1.00 \mathrm{a}$ & 0 \\
\hline C. zeylanicum EO (0.5\%)-Shellac & $0.00 \mathrm{f}$ & 100 & $0.13 e$ & 87 & $0.00 \mathrm{~g}$ & 100 & $0.19 d$ & 81 \\
\hline Carnauba & $1.00 \mathrm{a}$ & 0 & $1.00 \mathrm{a}$ & 0 & $1.00 \mathrm{a}$ & 0 & $1.00 \mathrm{a}$ & 0 \\
\hline C. zeylanicum EO (0.1\%)-carnauba & $0.77 b$ & 23 & $0.90 \mathrm{~b}$ & 10 & $0.90 \mathrm{~b}$ & 10 & $1.00 \mathrm{a}$ & 0 \\
\hline C. zeylanicum EO (0.5\%)-carnauba & $0.10 \mathrm{e}$ & 90 & $0.37 d$ & 63 & $0.17 \mathrm{ef}$ & 83 & $0.40 \mathrm{c}$ & 60 \\
\hline Paraffin & $1.00 \mathrm{a}$ & 0 & $1.00 \mathrm{a}$ & 0 & $1.00 \mathrm{a}$ & 0 & $1.00 \mathrm{a}$ & 0 \\
\hline C. zeylanicum EO (0.1\%)-paraffin & $0.80 \mathrm{~b}$ & 20 & $1.00 \mathrm{a}$ & 0 & $1.00 \mathrm{a}$ & 0 & $1.00 \mathrm{a}$ & 0 \\
\hline C. zeylanicum EO (0.5\%)-paraffin & $0.30 \mathrm{~d}$ & 70 & $0.58 \mathrm{c}$ & 42 & $0.38 \mathrm{~d}$ & 62 & $0.73 b$ & 27 \\
\hline Polyethylene & $1.00 \mathrm{a}$ & 0 & $1.00 \mathrm{a}$ & 0 & $1.00 \mathrm{a}$ & 0 & $1.00 \mathrm{a}$ & 0 \\
\hline C. zeylanicum EO (0.1\%)-polyethylene & $0.80 \mathrm{~b}$ & 20 & $1.00 \mathrm{a}$ & 0 & $1.00 \mathrm{a}$ & 0 & $1.00 \mathrm{a}$ & 0 \\
\hline C. zeylanicum EO (0.5\%)-polyethylene & $0.30 \mathrm{~d}$ & 70 & $0.58 \mathrm{c}$ & 42 & $0.38 \mathrm{~d}$ & 62 & $0.73 b$ & 27 \\
\hline Thiabendazole (0.4\%)-shellac & $0.00 \mathrm{f}$ & 100 & $0.03 \mathrm{f}$ & 97 & $0.00 \mathrm{~g}$ & 100 & $0.03 e$ & 97 \\
\hline
\end{tabular}

a Wound incidence was determined from two independent experiments.

Values in the same column marked with different letters are significantly different at $P \leq 0.05$ after LSD test.

C. zeylanicum EO at $0.1 \%$, regardless of the formulation, the pathogen species and the inoculation time. In addition, disease control was found to be reduced when treatment was applied $24 \mathrm{~h}$ instead of $4 \mathrm{~h}$ before inoculation, whatever the formulation and the pathogen species. In general, wound incidence was much more reduced for C. zeylanicum EO at $0.5 \%$ amended with Simulgel or wax than that amended with ethanol, irrespective of the pathogen species and the inoculation time. There were, however, some exceptions. In the case of inoculation by P. digitatum $24 \mathrm{~h}$ after treatment, wound incidence values were substantially identical for C. zeylanicum EO (0.5\%) formulations (ethanol, Simulgel, paraffin and polyethylene). Wound incidence was also much more reduced for C. zeylanicum $\mathrm{EO}$ at $0.5 \%$ amended with shellac and/or carnauba than with the other waxes (paraffin and polyethylene) and Simulgel, regardless of the pathogen species and the inoculation time. However, the most interesting treatment was with C. zeylanicum EO (0.5\%)-shellac, which allowed, as the fungicide (TZB), $100 \%$ of disease control when inoculation occurred $4 \mathrm{~h}$ after treatment whatever the pathogen. In this case of preventive treatment, the other C. zeylanicum $\mathrm{EO}(0.5 \%)$ formulations (shellac-carnauba-fatty acids, shellac-carnauba and carnauba) offered more than $75 \%$ of disease control.

Regarding the curative effect, fruit treatment was performed $24 \mathrm{~h}$ after inoculation with $P$. italicum. Only a concentration of $0.5 \%$ of C. zeylanicum was tested. Results are presented in Table 3. The application of $C$. zeylanicum EO supplemented with ethanol and Simulgel resulted respectively in $67 \%$ and $83 \%$ of disease control. The application of shellac, carnauba, or shellac-carnauba-fatty acids (XEDASOL M7) amended with C. zeylanicum EO (0.5\%) offered a total disease control like that of shellac amended with TBZ at $0.4 \%$. A good disease control (97\%) was also obtained with the application of C. zeylanicum EO (0.5\%) into shellac-carnauba. Regarding paraffin (95369-1L) or polyethylene (Michem ${ }^{\circledR}$ emulsion 18325) mixed with C. zeylanicum EO (0.5\%); disease control ( $81 \%$ and $85 \%$, respectively) was less than that of the other waxes and wound incidence was significantly different from that of the other waxes supplemented with $C$. zeylanicum EO but statistically similar to that of Simulgel supplemented with the same EO. As in the case of the preventive treatment, the mixture of $C$. zeylanicum $\mathrm{EO}$ and shellac and/or carnauba resulted in a greater reduction of wound incidence compared to that of C. zeylanicum EO and ethanol, Simulgel, paraffin or polyethylene.

Finally, these results (Tables 2 and 3) showed that disease control against the two most important postharvest pathogens was improved with C. zeylanicum EO mixed with Simulgel or waxes compared to the same EO at the same concentration mixed with ethanol. Since ethanol, Simulgel and waxes alone have no antifungal effect on the pathogen, this implies that efficacy of formulations (EO into ethanol, Simulgel or waxes) is only due to EO and not to a synergistic antifungal effect between EO and ethanol, Simulgel or waxes. The improvement of disease control is therefore related to the improvement of the EO efficacy, itself related to the product with which EO is associated (Simulgel and waxes in our study). Understanding the action of such products in improving EO efficacy and therefore disease control is thus more than necessary for the development of effective EO-based biofungicide formulations. This involves therefore, the search for the characteristics of products associated with EOs. 
Table 3

Incidence of blue mold of citrus on oranges by C. zeylanicum essential oil (EO) formulations applied $24 \mathrm{~h}$ after inoculation with P. italicum (curative treatment).

\begin{tabular}{|c|c|c|}
\hline $\begin{array}{l}\text { Treatment ( } 24 \mathrm{~h} \text { after } \\
\text { inoculation) }\end{array}$ & Wound incidence ${ }^{\mathrm{a}}$ & Disease control (\%) \\
\hline Distilled water (control) & $1.00 \mathrm{a}$ & 0 \\
\hline Ethanol & $1.00 \mathrm{a}$ & 0 \\
\hline $\begin{array}{l}\text { C. zeylanicum EO } \\
(0.5 \%)-\text { ethanol }\end{array}$ & $0.33 b$ & 67 \\
\hline Simulgel & $1.00 \mathrm{a}$ & 0 \\
\hline $\begin{array}{l}\text { C. zeylanicum EO } \\
(0.5 \%)-\text { Simulgel }\end{array}$ & $0.17 \mathrm{c}$ & 83 \\
\hline $\begin{array}{l}\text { Shellac-carnauba } \\
\text { wax-fatty acids }\end{array}$ & $1.00 \mathrm{a}$ & 0 \\
\hline $\begin{array}{l}\text { C. zeylanicum EO } \\
\text { (0.5\%)-shellac-carnauba } \\
\text { wax-fatty acids }\end{array}$ & $0.00 \mathrm{e}$ & 100 \\
\hline Shellac-carnauba & $1.00 \mathrm{a}$ & 0 \\
\hline $\begin{array}{l}\text { C. zeylanicum EO } \\
(0.5 \%) \text {-shellac-carnauba }\end{array}$ & $0.03 d$ & 97 \\
\hline Shellac & $1.00 \mathrm{a}$ & 0 \\
\hline $\begin{array}{l}\text { C. zeylanicum EO } \\
(0.5 \%) \text {-shellac }\end{array}$ & $0.00 \mathrm{e}$ & 100 \\
\hline Carnauba & $1.00 \mathrm{a}$ & 0 \\
\hline $\begin{array}{l}\text { C. zeylanicum EO } \\
(0.5 \%) \text {-carnauba }\end{array}$ & $0.00 \mathrm{e}$ & 100 \\
\hline Paraffin & $1.00 \mathrm{a}$ & 0 \\
\hline $\begin{array}{l}\text { C. zeylanicum EO } \\
(0.5 \%) \text {-paraffin }\end{array}$ & $0.19 c$ & 81 \\
\hline Polyethylene & $1.00 \mathrm{a}$ & 0 \\
\hline $\begin{array}{l}\text { C. zeylanicum EO } \\
(0.5 \%) \text {-polyethylene }\end{array}$ & $0.15 c$ & 85 \\
\hline $\begin{array}{l}\text { Thiabendazole } \\
(0.4 \%) \text {-shellac }\end{array}$ & $0.00 \mathrm{e}$ & 100 \\
\hline
\end{tabular}

a Wound incidence was determined from two independent experiments. Values in the same column marked with different letters are significantly different at $P \leq 0.05$ after LSD test.

Unlike alcohol, Simulgel and waxes increase the solubility of EOs into water-based products with a visible homogeneous aqueous dispersion, which leads to a consistent distribution of EO on the citrus fruit surface. This characteristic may contribute to the improvement of disease control. In addition, waxes form, after drying, a thin film around the fruit allowing a closer contact of EO with the fruit surface, which certainly contributes to the improvement of EO efficacy. Waxes have low permeability for water and gases (Baldwin, 1994; Baldwin et al., 1995; Hagenmaier, 2002; Srinivasa et al., 2004; Bourtoom, 2008; Zhou et al., 2008; Farag, 2010; Regnier et al., 2010), particularly advantageous for control of weight loss, maturation and quality of coated fruit and vegetables. It has been reported that the incorporation of EO into fruit or vegetable coating induces a significant reduction in $\mathrm{O}_{2}$ and water vapor permeability depending on EO concentration (Bosquez-Molina et al., 2003; Du Plooy et al., 2009; Regnier et al., 2010; Sanchez-Gonzalez et al., 2010a,b, 2011; Bonilla et al., 2012). This characteristic (low permeability to gases) of waxes may be responsible of the maintaining of $\mathrm{EO}$ on the fruit surface, thereby keeping high concentrations of EO for extended periods of time. It may explain why EO in waxes was more effective in reducing the levels of blue and green rots than EO at the same concentration in alcohol or in Simulgel.

Among EO-wax formulations, different levels of wound incidence (disease control) were observed even when they all have the same EO concentration. Du Plooy et al. (2009) studied the effect of different commercial waxes (MS1 and carnauba tropical formulations) supplemented with different EOs (e.g. L. scaberrima and Mentha spicata) as an alternative to synthetic fungicides in citrus postharvest management against $P$. digitatum. As in the present work, excellent disease control was achieved depending on the EO-wax combination, while waxes alone showed no disease control. Using the same commercial coatings supplemented with the

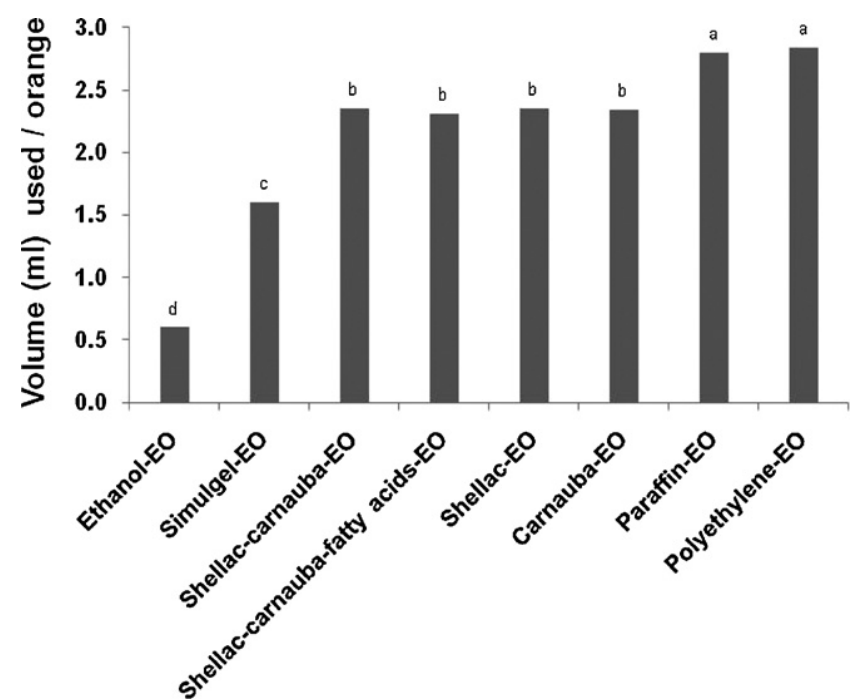

\section{C. zeylanicum EO (0.5\%)-wax formulations}

Fig. 1. Volume $(\mathrm{mL})$ used per orange (adherence) of $C$. zeylanicum EO formulations. Different letters indicate significant differences at $P \leq 0.05$ after LSD test.

same EOs (2500 $\mu \mathrm{L} / \mathrm{L})$ as Du Plooy et al. (2009) and Regnier et al. (2010) also observed in their study that the effectiveness of an EO on avocado fruit against Colletotrichum gloeosporioides and Lasiodiplodia theobromae depended on the wax used. L. scaberrima EO-MS865 is more effective than $L$. scaberrima EO-carnauba whereas M. spicata EO-carnauba is more effective than M. spicata EO-MS865. In our study, C. zeylanicum EO (0.5\%) efficacy was improved (in the preventive treatment) when supplemented with shellac than with the other waxes (carnauba, paraffin and polyethylene). This may be due to the lower permeability for gases of shellac compared to the other waxes (Mannheim and Soffer, 1996; Alleyne and Hagenmaier, 2000; Bai et al., 2003), thus keeping more EO on fruit surface. Moreover, for the same EO-wax formulation, disease control was reduced when treatment was done $24 \mathrm{~h}$ versus $4 \mathrm{~h}$ before citrus fruit infection. This is probably due to the release of EO over time because of high volatility. We are currently studying the effect of these waxes on EO volatilization. Preliminary results showed that fruit treated $24 \mathrm{~h}$ before inoculation seemed to keep less EO on their surfaces, which make them more vulnerable to infection than fruit treated $4 \mathrm{~h}$ before inoculation. Although there is a significant decrease in the effectiveness of the EO after $24 \mathrm{~h}$, the disease control due to EO-wax formulations is relatively acceptable because more than half of the wounds were protected.

Our results also showed that the curative effect of $C$. zeylanicum EO seems more marked than its preventive effect. This may be explained by the immediate effect of EO formulations on pathogen development in the curative treatment (no volatilization effect) and/or by the possible vulnerability of the pathogen to the treatment $24 \mathrm{~h}$ after its inoculation.

\subsection{Volume of treatment per orange (adherence)}

Only a concentration of $0.5 \%$ of C. zeylanicum EO was tested. The volume of treatment used per orange is presented in Fig. 1. The lowest volume of treatment $(0.60 \mathrm{~mL})$ was recorded for EO-ethanol while the highest one $(2.80-2.84 \mathrm{~mL})$ was for EO-wax (paraffin and polyethylene). The volume of treatment of C. zeylanicum EO-Simulgel $(1.60 \mathrm{~mL})$ was more than double that of EO-ethanol. For the other C. zeylanicum EO-wax (shellac, carnauba, shellac-carnauba or shellac-carnauba-fatty acids) formulations, volumes ranging from 2.31 to $2.35 \mathrm{~mL}$ were recorded. These results, associated with those previously presented (Tables 1 and 2), 


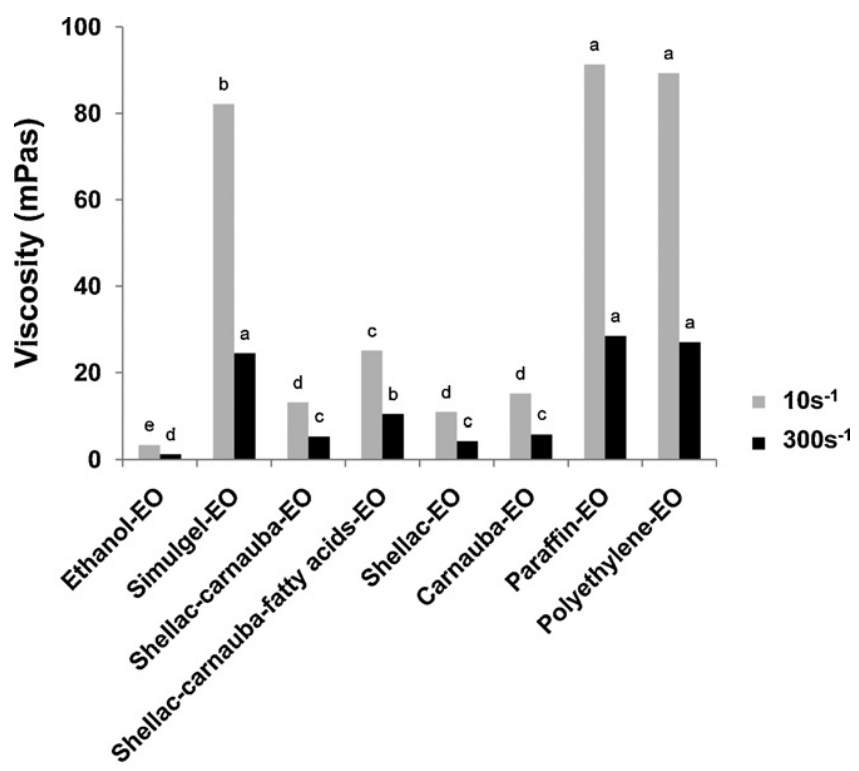

C. zeylanicum EO (0.5\%)-wax formulations

Fig. 2. Viscosity (mPas) (rotational rheology) of C. zeylanicum EO formulations. Rheological measurements of $C$. zeylanicum EO formulations were performed in duplicate by a rotational viscometer (Bohlin Instruments CVO50 Rheometer) at $25^{\circ} \mathrm{C}$. Curves of instantaneous viscosity (mPas) as a function of the shear rate $(D)$ were obtained with the following program: $5 \mathrm{~min}$ from 0 to $300 \mathrm{~s}^{-1}$ (the maximum shear rate). Viscosity of each formulation at $10 \mathrm{~s}^{-1}$ and $300 \mathrm{~s}^{-1}$ was determined from the curve. For each shear rate, different letters indicate significant differences at $P \leq 0.05$ after LSD test.

indicate that treatment efficacy is correlated with the volume of treatment which remains on the orange fruit skin. The greater the volume of formulation treatment adhering on the fruit surface, the better the disease control. Indeed, once dried, waxes formed a thin film around the fruit, keeping therefore more formulation (i.e. more EO) on the fruit surface, resulting in better disease control than ethanol and Simulgel. With regard to C. zeylanicum EO amended with wax (shellac, carnauba, shellac-carnauba or shellac-carnauba-fatty acids), similar volumes of treatment were used per orange (Fig. 1) while significant differences in wound incidence were observed (Table 2). In addition, the volume of the treatment of $C$. zeylanicum EO amended with paraffin or polyethylene wax was significantly superior to that of $C$. zeylanicum EO amended with the other waxes. However, disease control afforded by formulations based on C. zeylanicum EO and paraffin or polyethylene waxes was found to be less important than those based on the other waxes. This shows that disease control by EO-waxes is not dependent only on the volume that remains on the fruit skin, but also, probably on the retention of EO components on the fruit. Maintaining EO on the fruit for extended periods of time may be related to the compatibility (affinity) between EO compounds and those of waxes. Such compatibility may play an important role in improving EO efficacy.

\subsection{Rotational rheological}

Only a concentration of $0.5 \%$ of $C$. zeylanicum was tested. Viscosity of C. zeylanicum EO formulations is presented in Fig. 2. Whatever the EO formulation, there was a decrease of viscosity when going from $10 \mathrm{~s}^{-1}$ to $300 \mathrm{~s}^{-1}$; this implies that the behavior of EO formulations was shear-thinning (or pseudoplastic) in all cases and thus could be used during some processing operations (when it is pumped in a machine, for instance). The formulation based on C. zeylanicum EO-Simulgel was significantly more viscous than that of C. zeylanicum EO-wax (shellac, carnauba, shellac-carnauba or shellac-carnauba-fatty acids) and C. zeylanicum-ethanol, but less than that of C. zeylanicum EO-wax (paraffin or polyethylene). In terms of viscosity, the formulation based on C. zeylanicum EO-Simulgel was significantly different and $\sim 5$ times superior to that of Simulgel alone while there was no significant difference between the formulation based on C. zeylanicum EO-wax (shellac, carnauba, shellac-carnauba, shellac-carnauba-fatty acids, paraffin or polyethylene) and waxes alone (data not shown).

If we compare the formulation based on C. zeylanicum EO-ethanol with the other formulations, it seems that a higher viscosity of the formulation leads to its greater adherence to the fruit surface (i.e. more EOs) and therefore better disease control. For $C$. zeylanicum EO-wax and C. zeylanicum EO-Simulgel formulations, however, the best disease control was not always associated with the highest levels of adherence and viscosity. In addition, whatever the formulation of $C$. zeylanicum EO-wax (shellac, carnauba, shellac-carnauba or shellac-carnauba-fatty acids), the volumes of treatment were significantly the same, while their viscosity and preventive action were significantly different. Therefore, viscosity of formulations cannot alone explain the improvement of $C$. zeylanicum EO efficacy. It may be a combined action of the solubility, viscosity, adherence, permeability of $C$. zeylanicum EO-wax formulations, and certainly the compatibility (affinity) between EO compounds and those of waxes that allow retaining $\mathrm{EO}$ on the fruit surface, which improve EO efficacy.

\subsection{Practical aspects}

EOs are considered as GRAS (Generally Recognized As Safe) and thus their application for the protection of fruit and vegetables should not pose regulatory problems. But practical application of EOs still remains expensive, which limits their use in the preservation of fruit and vegetables. The incorporation of EOs into coating formulations appears to be a good strategy to reduce application costs since EO quantities can be reduced. In this study, the effective concentration of $C$. zeylanicum EO allowing 100\% disease control was improved (reduced) by up to $0.5 \%$ by incorporating C. zeylanicum EO into shellac wax (preventive treatment), compared to our previous study (Kouassi et al., 2010) where an effective concentration of $C$. zeylanicum EO into ethanol was $5 \%$. At such a concentration of $0.5 \%, \sim 60 \mathrm{~mL}$ of $C$. zeylanicum EO mixed with about $11,840 \mathrm{~mL}$ of shellac are necessary to treat one ton of citrus fruit. According to prices currently available on the market (Pranarôm international SA, Sigma-Aldrich), the average cost of such a quantity of EO is about six times that of the tested chemical fungicide necessary to treat the same quantity of orange fruit. It is thus clear that for such biofungicides, other expenses related to their development, registration, distribution, etc. will be added to the purchase cost. A possible way to reduce treatment costs is to combine $C$. zeylanicum and other relatively cheaper EOs. This has proved possible in in vitro conditions where the biological activity of $C$. zeylanicum alone was similar to that of $C$. zeylanicum-C. verum-E. caryophyllata mixture (at equal volumes) provided that final concentrations are superior to $0.02 \%$ (unpublished results). If these results are confirmed in vivo (ongoing study), the use of the mixture at equal volumes of these three EOs at a final concentration of $0.5 \%$ would allow a reduction of half the cost of EOs necessary to treat a ton of fruit compared with the use of $C$. zeylanicum alone. It is thus clear that treatment by EOs would cost a little more than treatment by the tested chemical fungicide. However, the benefits of EOs (eco-compatible, non-toxic at low doses, biodegradable, and no risk for resistance development) and disadvantages of chemical fungicides on health and on the environment make EOs more interesting for citrus postharvest treatment. The preventive and curative effects of $C$. zeylanicum EO could make it an excellent biofungicide candidate, because a 
postharvest treatment by this oil would prevent the development of both latent preharvest and postharvest infections.

\section{References}

Alleyne, V., Hagenmaier, R.D., 2000. Candelilla-shellac-an alternative formulation for coating apples (Malus domestica Borkh.). Hortscience 35, 691-693.

Amiri, A., Dugas, R., Pichot, A.L., Bompeix, G., 2008. In vitro and in vivo activity of eugenol oil (Eugenia caryophyllata) against four important postharvest apple pathogens. International Journal of Food Microbiology 126, 13-19.

Bai, J., Hagenmaier, R.D., Baldwin, E.A., 2003. Coating selection for 'Delicious' and other apples. Postharvest Biology and Technology 28, 381-390.

Bakkali, F., Averbeck, S., Averbeck, D., Idaomar, M., 2008. Biological effects of essential oils. Food and Chemical Toxicology 46, 446-475.

Baldwin, E.A., 1994. Edible coatings for fresh fruits and vegetables: past, present and future. In: Krochta, J.M., Baldwin, E.A., Nisperos-Carriedo, M.O. (Eds.), Edible Coatings and Films to Improve Food Quality. Technomic Publishing, Lancaster, PA, pp. 25-64.

Baldwin, E.A., Nisperoscarriedo, M., Shaw, P.E., Burns, J.K., 1995. Effect of coatings and prolonged storage conditions on fresh orange flavor volatiles, degrees brix, and ascorbic acid levels. Journal of Agricultural and Food Chemistry 43, 1321-1331.

Bonilla, J., Atarés, L., Vargas, M., Chiralt, A., 2012. Edible films and coatings to prevent the detrimental effect of oxygen on food quality: possibilities and limitations. Journal of Food Engineering 110, 208-213.

Bosquez-Molina, E., Guerrero-Legarreta, I., Vernon-Carter, E.J., 2003. Moisture barrier properties and morphology of mesquite gum-candelilla wax based edible emulsion coatings. Food Research International 36, 885-893.

Bourtoom, T., 2008. Edible films and coatings: characteristics and properties. International Food Research Journal 15, 237-248.

Campaniello, D., Corbo, M.R., Sinigaglia, M., 2010. Antifungal activity of eugeno against Penicillium, Aspergillus, and Fusarium species. Journal of Food Protection 73, 1124-1128.

Combrinck, S., Regnier, T., Kamatou, G.P.P., 2011. In vitro activity of eighteen essential oils and some major components against common postharvest fungal pathogens of fruit. Industrial Crops and Products 33, 344-349.

Daferera, D.J., Basil, N., Ziogas, N., Polissiou, M.G., 2003. The effectiveness of plant essential oils on Botrytis cinerea, Fusarium sp and Clavibacter michiganensis subsp. Michiganensis. Crop Protection 22, 39-44.

De Sousa, P.P.R., de Oliveira Pereira, F., de Sousa Lima, R., de Oliveira Lima, E., 2011. Antifungal action of Cinnamomum zeylanicum Blume essential oil against Penicillium spp from environment air of a dry food industry. International Research Journal of Microbiology 2,173-178.

Du Plooy, W., Regnier, T., Combrinck, S., 2009. Essential oil amended coatings as alternatives to synthetic fungicides in citrus postharvest management. Postharvest Biology and Technology 53, 117-122.

Farag, Y., 2010. Characterization of different shellac types and development of shellac-coated dosage forms. Ph.D. dissertation. Hamburg University http://www.chemie.uni-hamburg.de/bibliothek/2010/DissertationFarag.pdf.

Hagenmaier, R.D., 2002. The flavor of mandarin hybrids with different coatings. Postharvest Biology and Technology 24, 79-87.

Hummelbrunner, L.A., Isman, M.B., 2001. Acute, sublethal, antifeedant, and a synergistic effect of monoterpenoid essential oil compounds on the tobacco cutworm Spodoptera litura (Lep., Noctuidae). Journal of Agricultural and Food Chemistry 49, 715-720.

Kouassi, K.H.S., Bajji, M., Brostaux, Y., Zhiri, A., Samb, A., Lepoivre, P., Jijakli, M.H Development and application of a microplate method to evaluate the efficacy of 30 essential oils against Penicillium italicum, P. digitatum and Colletotrichum musea, three postharvest fungal pathogens on fruit. Biotechnology, Agronomy, Society and Environment, in press.

Kouassi, K.H.S., Bajji, M., Zhiri, A., Lepoivre, P., Jijakli, M.H., 2010. Evaluation of three essential oils as potential sources of botanical fungicides. Communications in Agricultural and Applied Biological Science 75, 525-529.
Linde, J.H., Combrinck, S., Regnier, T.J.C., Virijevic, S., 2010. Chemical composition and antifungal activity of the essential oils of Lippia rehmannii from South Africa. South African Journal of Botany 76, 37-42.

Mannheim, C.H., Soffer, T., 1996. Permeability of different wax coatings and their effect on citrus fruit quality. Journal of Agricultural and Food Chemistry 44 , 919-923.

Marei, G.I.Kh., Abdel Rasoul, M.A., Abdelgaleil, S.A.M., 2012. Comparative antifungal activities and biochemical effects of monoterpenes on plant pathogenic fungi. Pesticide Biochemistry and Physiology 103, 56-61.

Matan, N., Saengkrajang, W., Matan, N., 2011. Antifungal activities of essential oils applied by dip-treatment on areca palm (Areca catechu) leaf sheath and persistence of their potency upon storage. International Biodeterioration and Biodegradation 65, 212-216.

Moon, S.-E., Kim, H.-Y., Cha, J.-D., 2011. Synergistic effect between clove oil and its major compounds and antibiotics against oral bacteria. Archives of Oral Biology $56,907-916$.

Plotto, A., Roberts, D.D., Roberts, R.G., 2003. Evaluation of plant essential oils as natural postharvest disease control of tomato (Lycopersicon esculentum). Acta Horticulturae 628, 737-745.

Ranasinghe, L., Jayawardena, B., Abeywickrama, K., 2002. Fungicidal activity of essential oils of Cinnamomum zeylanicum (L.) and Syzygium aromaticum (L.) Merr et L.M. Perry against crown rot and anthracnose pathogens isolated from banana. Letters in Applied Microbiology 35, 208-211.

Regnier, T., Combrinck, S., Du Plooy, W., Botha, B., 2010. Evaluation of Lippia scaberrima essential oil and some pure terpenoid constituents as postharvest mycobiocides for avocado fruit. Postharvest Biology and Technology 57 $176-182$.

Sanchez-Gonzalez, L., Chafer, M., Chiralt, A., Gonzalez-Martinez, C., 2010a. Physical properties of chitosan films containing bergamot essential oil and their inhibitory action on Penicilium italicum. Carbohydrate Polymers 82, 277-283.

Sanchez-Gonzalez, L., Gonzalez-Martinez, C., Chiralt, A., Chafer, M., 2010b. Physical and antimicrobial properties of chitosan-tea tree essential oil composite films. Journal of Food Engineering 98, 443-452.

Sanchez-Gonzalez, L., Vargas, M., Gonzalez-Martinez, C., Chiralt, A., Chafer, M., 2011. Use of essential oils in bioactive edible coatings. Food Engineering Reviews 3 , $1-16$.

Sen-Sung, C., Ju-Yun, L., Ed-Haun, C., Shang-Tzen, C., 2008. Antifungal activity of cinnamaldehyde and eugenol congeners against wood-rot fungi. Bioresource Technology 99, 5145-5149.

Şerban, E.S., Ionescu, M., Maier, D.M.C.S., Bojita, M.T., 2011. Screening of the antibacterial and antifungal activity of eight volatile essential oils. Farmacia 59, 440-446.

Sheng-Yang, W., Pin-Fun, C., Shang-Tzen, C., 2005. Antifungal activities of essential oils and their constituents from indigenous cinnamon (Cinnamomum osmophloeum) leaves against wood decay fungi. Bioresource Technology 96 813-818.

Soylu, E.M., Kurt, S.., Soylu, S., 2010. In vitro and in vivo antifungal activities of the essential oils of various plants against tomato grey mould disease agent Botrytis cinerea. International Journal of Food Microbiology 143 $183-189$.

Srinivasa, P.C., Susheelamma, N.S., Ravi, R., Tharanathan, N.R., 2004. Quality of mango fruit during storage: effect of synthetic and ecofriendly films. Journal of the Science of Food and Agriculture 84, 818-824.

Teuscher, E., Anton, R., Lobstein, A., 2005. Plantes aromatiques: Epices, aromates, condiments et huiles essentielles. Editions Tec \& Doc, Paris, France.

Tsair-Bor, Y., Shang-Tzen, C., 2008. Synergistic effects of cinnamaldehyde in combination with eugenol against wood decay fungi. Bioresource Technology 99 , 232-236.

Zhou, R., Mo, Y., Li, Y.F., Zhao, Y.Y., Zhang, G.X., Hu, Y.S., 2008. Quality and internal characteristics of huanghua pears (Pyrus pyrifolia Nakai, cv. Huanghua) treated with different kinds of coatings during storage. Postharvest Biology and Technology 49, 171-179. 